\title{
Scales of Mytilus spp. population dynamics: importance of adult displacement and aggregation
}

\author{
Filip Petrović, Frédéric Guichard*
}

Department of Biology, McGill University, 1205 Docteur Penfield, Montreal, Québec H3A 1B1, Canada

\begin{abstract}
The control of mussel population dynamics by larval supply and by more local processes affecting post-recruitment survival and growth has received considerable attention. However, immigration and emigration of adults and their contribution to colonization dynamics remain largely unknown. We manipulated the location and density of marked mussels in experimental transplants in the St. Lawrence Estuary (Québec). Our results reveal that colonization by Mytilus spp. is influenced by (1) passive adult movement through wave disturbance and immigration, (2) spatial aggregation and (3) topographic heterogeneity. Results show that $\sim 90 \%$ of colonization in experimental plots was by individuals of 4 to $32 \mathrm{~mm}$ shell length and was associated with both withintransplant and local $(<0.15 \mathrm{~m}$ from transplant) aggregation. Experimental gaps revealed a similarly aggregated wave-disturbance process, propagating small $(0.5 \mathrm{~m})$ gaps across $>100 \mathrm{~m}$. The passive displacement distribution of marked and wave-dislodged individuals further revealed movement distance ranging from 1 to $150 \mathrm{~m}$ and disturbance mortality from $<20$ to $40 \%$. Together our results reveal that colonization in subarctic mussel populations can be largely controlled by cycles of adult displacement and further aggregation at the landscape level $(\sim 100 \mathrm{~m})$. Such positive feedbacks involved in disturbance and colonization could explain strong fluctuations in abundance and challenge the interpretation of intertidal populations as systems mostly limited by larval supply and post-recruitment survival.
\end{abstract}

KEY WORDS: Disturbance - Aggregation - Scale dependence - Mussel displacement distribution · Rocky intertidal landscape $\cdot$ Spatial dynamics

Resale or republication not permitted without written consent of the publisher

\section{INTRODUCTION}

Understanding the processes of disturbance and recolonization that regulate populations and communities is a fundamental theme in ecology (Sousa 1984, Connell et al. 1997). In rocky intertidal ecosystems, physical disturbance by such agents as wave action and ice scour has been studied as a factor controlling community structure and diversity (Paine \& Levin 1981, McCook \& Chapman 1997). Much progress has been achieved through the assumption of open systems (Levin \& Paine 1974, Roughgarden et al. 1985), with larval supply and post-recruitment survival and growth as the main processes of recovery following mortality induced by disturbance (Underwood \& Denley 1984). Disturbance is thus strongly associated with mortality, and its contribution as a force of adult displacement and of local recolonization is largely undetermined (but see Hunt \& Scheibling 2001, 2002). Here, we reveal and quantify the scales of adult displacement following wave disturbance, and of spatial aggregation (colonization close to conspecifics) in a subarctic mussel population.

In mussel populations, colonization and recovery after disturbance can be influenced by biotic and abiotic factors affecting both recruitment and postrecruitment survival (Menge et al. 1997). Early studies emphasized the importance of local processes such as competition, predation and physical disturbance (Dayton 1971, Paine 1974). More recently ecologists shifted their focus to larger scales, considering oceanographic control of larval supply to be a predominant factor dic- 
tating patterns of distribution (Gaines \& Roughgarden 1985, Menge et al. 2003). As a result, local marine populations are often considered to be demographically open, where local recruitment is decoupled from local reproduction by the dispersal of larvae (Caley et al. 1996). In an open population, the gains and losses of sessile individuals occur solely via recruitment, growth and mortality (Connell 1985). Therefore, postsettlement displacement of adults in sessile species such as mussels remains virtually unexplored at scales that can directly regulate populations.

Passive migration of adult mussels by wave dislodgement has been documented (Hunt \& Scheibling $1998,2001,2002)$, but the contribution of adult displacement to population dynamics across spatial scales and body sizes has not been resolved. Mussel movement at very small body size or spatial scales have been shown to contribute to mussel distribution and growth. For example, passive movement of post-larvae has been associated with secondary settlement behaviour (Bayne 1964, Sigurdsson et al. 1976). Juvenile and adult individuals also display active small-scale movement as they migrate vertically (Schneider et al. 2005) and laterally within mussel beds after disturbance (Paine \& Levin 1981, Littorin \& Gilek 1999). More recently, Hunt \& Scheibling (2001) showed that small (2 to $10 \mathrm{~mm}$ shell length) individuals could account for 15 to $20 \%$ of mussel colonization in experimental patches. Here, we quantify the spatial scale of such passive movement and test its importance across body size. We also address the dynamic processes coupling adult displacement and aggregation to wave disturbance across intertidal mussel beds.

We report results from experimental mussel transplants and gaps to test the importance of adult displacement and recruitment, within-transplant and local (between quadrats, $<0.15 \mathrm{~m}$ from transplants) aggregation near conspecifics, and topographic heterogeneity, during colonization by mussels on a subarctic rocky intertidal habitat. Our results demonstrate the importance of movement by adult-sized mussels (>4 mm shell length) over scales of landscapes (10 to $100 \mathrm{~m}$ ) for colonization occurring during the main recruitment period. We tested for the body-size-dependent role of topography and of both within-transplant and local aggregation during colonization, and revealed the size-dependent propagation of experimental gaps across a natural mussel bed. Our results suggest that within-year mussel population dynamics at the scale of subarctic landscapes can largely operate through the passive and spatially correlated movement of adults during disturbance and colonization. These findings should have important consequences for the understanding of large-scale dynamics of intertidal ecosystems.

\section{MATERIALS AND METHODS}

Study area. The study area is located in a subarctic region on the south shore of the St. Lawrence Estuary in Sainte-Flavie, Québec, Canada (Fig. 1). The $700 \mathrm{~m}$ stretch of rocky shoreline chosen to conduct this study was relatively straight and displayed no major topographical features or freshwater outflows. The experiments were carried out in the mid-intertidal zone, over a $350 \mathrm{~m}$ stretch for the mussel colonization experiment and over a $100 \mathrm{~m}$ mussel bed for the artificial gap disturbance experiment, $250 \mathrm{~m}$ from the closest colonization experiment site (Fig. 1).

The tide cycle is semi-diurnal, and the mean and maximal tidal amplitudes are 2.0 and $4.5 \mathrm{~m}$, respectively. The surface-water salinity and temperature in this region of the estuary during the summer months are typically 26 to $27 \mathrm{ppt}$ and 12 to $14^{\circ} \mathrm{C}$ (Fradette \& Bourget 1980). Ice scouring is an important cause of disturbance at the end of the winter, scraping exposed organisms off the bedrock (Bergeron \& Bourget 1986). The intertidal community in our study area is dominated by mussels and fucoid algae. Two Mytilus species, M. edulis and $M$. trossulus, have been reported in the St. Lawrence Estuary (McDonald et al. 1991), with



Fig. 1. Gulf of St. Lawrence, Québec, Canada. The study area is located east of Ste. Flavie, on the south shore of the estuary. The westernmost colonization site and easternmost disturbance site are situated at $48^{\circ} 37.64^{\prime} \mathrm{N}, 68^{\circ} 12.06^{\prime} \mathrm{W}$ and $48^{\circ} 37.82^{\prime} \mathrm{N}, 68^{\circ} 11.58^{\prime} \mathrm{W}$, respectively 
no morphological differences that make them clearly distinguishable. Other related Mytilus species have been shown to differ in their attachment strength (Bell \& Gosline 1997) and in their movement rate (Schneider et al. 2005), and M. edulis and M. trossulus can show different tolerance to salinity in the laboratory (Qiu et al. 2002). However, studies in the Gulf of St. Lawrence showed no ecological differences between species in natural habitats (Moreau et al. 2005). Moreover, their distribution in the St. Lawrence Estuary and their occurrence in our study area are still unknown, and it has been suggested to be highly heterogeneous in the Gulf of St. Lawrence (Moreau et al. 2005) and in the Gulf of Maine (Rawson et al. 2007). For the purpose of this study, they are considered ecologically equivalent and are hereafter referred to as Mytilus spp. Marine snails of the Littorina genus are also abundant in this region. The gastropod Nucella (Thais) lapillus, a predator of mussels, was rarely witnessed at the lower edge of the intertidal zone in our study area. In addition, waterfowl were seldom observed, and predation pressure is therefore assumed to have no substantial impact on Mytilus spp. populations in our study area (see also Guichard et al. 2001).

Mussel colonization experiment. To examine the effect of density and topographic heterogeneity (presence of a crevice) on Mytilus spp. colonization rates, we placed mussel transplants on cleared sites in the mid-intertidal zone. One hundred $50 \times 50 \mathrm{~cm}$ sites (Fig. 2) were selected based on the following criteria: all were centred on crevices 5 to $10 \mathrm{~cm}$ wide and 2 to $4 \mathrm{~cm}$ deep. Crevices were located on bedrock with $<10^{\circ}$ inclination. There were no tide pools nor topographical irregularities $>20 \mathrm{~cm}$ within $1 \mathrm{~m}$ of each site. The range in elevation among sites was $40 \mathrm{~cm}$, resulting in immersion time differences $<40 \mathrm{~min}$. Of these sites, 45 were then randomly selected and cleared of all benthic organisms. Each selected site also included a $10 \mathrm{~cm}$ cleared buffer zone, hence excluding any contribution of active mussel movement to colonization into experimental sites (Hunt \& Scheibling 1998); 15 sites were kept as controls (no mussel transplant), 15 sites received a low-density transplant (50 mussels), and 15 sites received a high-density transplant (175 mussels; Fig. 2). Mussel bed density in our study area prior to the experiment was highly variable and ranged from our low-density transplant size to a mussel bed covering $100 \mathrm{~m}$ (see 'Artificial gap experiment' below).
Transplant mussels: We collected 3375 mussels with shell lengths of 25 to $40 \mathrm{~mm}$ at an independent location $3 \mathrm{~km}$ downstream of our experimental site. This shell length interval included the mode of mussel size distribution in our study system, while smaller and larger individuals were in low densities and could have introduced among-transplant variability in shell-length distribution. Mussels were air dried for $1 \mathrm{~h}$, after which the shells were sanded to enhance paint adherence. Mussels were then numbered and colour-coded to their respective site (1 colour per treatment level and 1 to 15 site numbers) using bright coloured latex paint. Finally, a thin coat of clear epoxy glue was applied on the numbered paint marks to withstand field conditions, allowing transplant mussels to remain identifiable throughout the season. Before putting the mussel transplants out in the field, transplant mussels were held in perforated food containers placed in indoor basins with unfiltered estuarine water for $1 \mathrm{wk}$. This eased the establishment of an initial aggregation via byssal thread formation, facilitating their on-site transplantation and survival.

Mussels were transplanted to experimental sites after they were cleared of organisms in mid-May. Mussel transplants were positioned on the crevice in the centre of the site and restrained with flexible plastic mesh for $1 \mathrm{wk}$, thus enabling them to attach to the substrate without being dislodged by waves.

After the plastic mesh was removed, transplant mussels were exposed to wave disturbances and some indi-

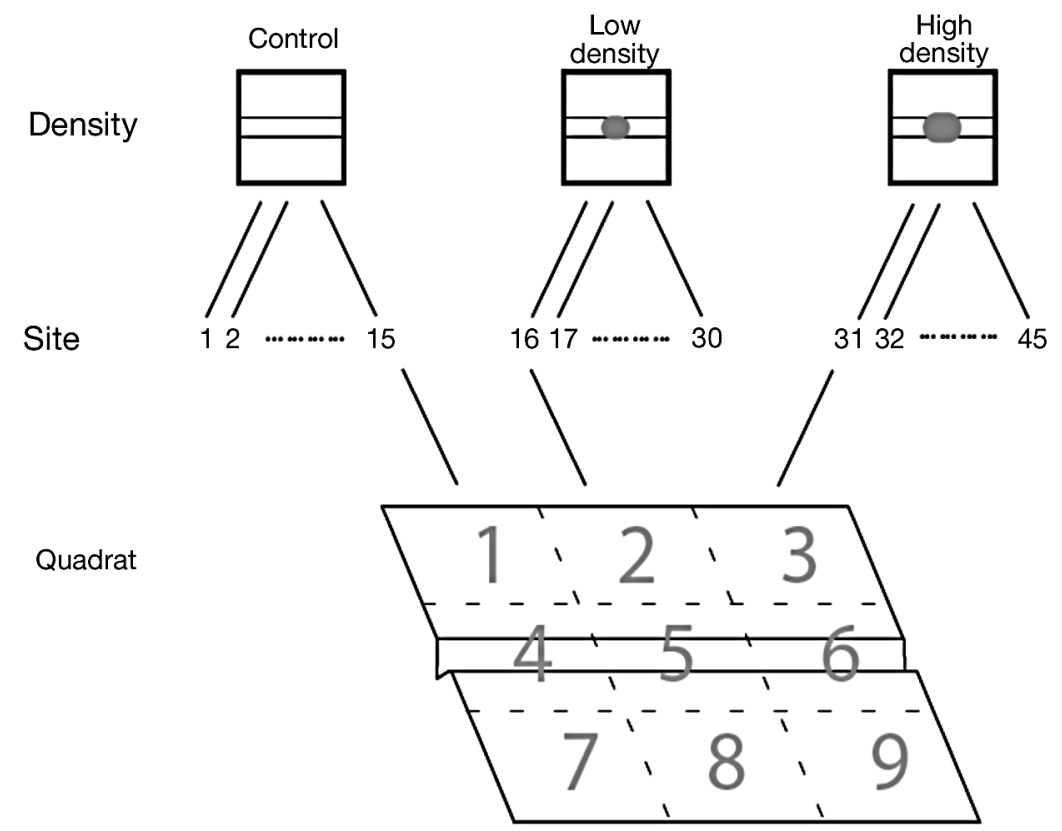

Fig. 2. Experimental design for the transplant colonization experiment. Cleared sites $(\mathrm{n}=45)$ are $50 \times 50 \mathrm{~cm}$ and divided into 9 quadrats. Quadrats 1 to 3 and 7 to 9 represent smooth substrata. Quadrats 4 to 6 are superimposed on crevices, with Quadrat 5 on the experimental transplant 
viduals were dislodged from transplants and passively moved throughout the intertidal zone during the summer. We surveyed our study area (30 man hours) in early August, and recorded the position of all transplant mussels that were found outside of their experimental site. Individual mussels were identified by the colour code of their treatment level and site number and their position $( \pm 5 \mathrm{~mm}$ ) was measured using a total surveying station (Leica TC705). Distance and orientation of displacement were recorded for 84 individuals.

Collecting and processing of samples: Experimental sites were sampled from mid- to late August. Each site was divided into 9 quadrats (Fig. 2). Quadrats 1 to 3 and 7 to 9 were on smooth surfaces, while Quadrats 4 to 6 included the crevice. The centre quadrat (5) is the location of the mussel transplant. All organisms were scraped from each quadrat and kept frozen $\left(-18^{\circ} \mathrm{C}\right)$ until they could be processed in the laboratory. Each sample was shaken through 4 sieves $(9.5,4.0,2.0$, and $0.5 \mathrm{~mm}$ mesh size), and density and blotted weight $( \pm 0.005 \mathrm{~g})$ of all species were determined for each size class. Mytilus spp. size classes based on sieves reflect shell width rather than shell length. Table 1 shows shell lengths (mm) of a sub-sample of 181 mussels collected across sieve mesh sizes. We conservatively labelled as 'recruits' (i.e. individuals that recruited on the year of our experiment) all mussels retrieved in the $0.5 \mathrm{~mm}$ mesh sieve (1.9 to $3.9 \mathrm{~mm}$ shell length; Table 1). Mussels retrieved in larger sieves were thus identified as larger juvenile and adult mussels assumed to have recruited in previous years (hereafter referred to as adults). Mytilus spp. larvae have a single settlement period each year, and settle at a shell length of 250 to $400 \mu \mathrm{m}$ (Bayne 1965). In this region, Mytilus spp. settlement peaks in late July and lasts until early August. It is unlikely that recruits in a subarctic intertidal environment would reach a shell length $>3.9 \mathrm{~mm}$ within 1 mo when compared to growth of subtidal individuals (Kautsky 1982). Based on individual size at settlement ( $<0.5 \mathrm{~mm}$ shell length), it is also possible that some recruits were too small to be retained on the $0.5 \mathrm{~mm}$ sieve. However, based on $M$. edulis morphology (Stirling \& Okumus 1994; Table 1 in present paper), individuals as small as $1.0 \mathrm{~mm}$ should be col-

Table 1. Mytilus spp. Mean \pm SD (min.-max.) shell lengths of colonizing mussels at transplant sites for each sieve size class based on a sub-sample $(\mathrm{n}=181)$

\begin{tabular}{|lc|}
\hline Sieve size class $(\mathrm{mm})$ & Shell length $(\mathrm{mm})$ \\
\hline 0.5 & $3.03 \pm 0.54(1.90-3.94)$ \\
2.0 & $5.92 \pm 0.96(4.02-7.90)$ \\
4.0 & $10.59 \pm 2.63(6.57-17.17)$ \\
9.5 & $23.94 \pm 3.51(17.80-31.77)$ \\
\hline
\end{tabular}

lected in the $0.5 \mathrm{~mm}$ sieve, suggesting that the observed minimum shell length of $1.9 \mathrm{~mm}$ was the smallest individual size in our quadrats.

Artificial gap experiment. To quantify the propagation rate of wave disturbances, we created artificial gaps in a large mussel bed in the mid-intertidal zone. This mussel bed neared $100 \mathrm{~m}$ in length and $20 \mathrm{~m}$ in its widest section. We selected 60 potential sites for the artificial gaps, of which half were randomly chosen. Potential sites were not located within $1 \mathrm{~m}$ of a large boulder (>50 cm in diameter), and all sites were within an elevation range of $30 \mathrm{~cm} ; 10$ sites were set as control (undisturbed), 10 sites received a small $(25 \times 25 \mathrm{~cm})$ and 10 sites received a large $(50 \times 50 \mathrm{~cm})$ disturbance $(\mathrm{gap})$.

The artificial gaps were created in mid-August. The front edge of each gap was parallel to shore. All of the mussel cover within each gap was removed, and the mussels were released at an independent site. Artificial gaps and controls were marked with screws imbedded into surrounding rocks and boulders. The exact position $( \pm 5 \mathrm{~mm})$ in 3 -dimensional space of each screw was determined via the use of a total station. Photographs of all experimental gaps and controls, including geo-referenced points, were taken at 5.1 megapixel resolution. The camera was fastened to a retractable boom and centred over a site at approximately $3.5 \mathrm{~m}$ above the mussel bed. Photographs were taken before and after gap creation, the following day and $10 \mathrm{~d}$ later. The sites were photographed again during fall (21 October 2004), as well as at the end of spring of the following year (9 June 2005). The photographs were rectified and analysed using Adobe Photoshop. A $3 \times 3 \mathrm{~m}$ square delimiting the same field of view throughout the time series at each site was superimposed on each photograph to document the changes in gap size over time.

Water flow measurement. Plaster of Paris cylinders were placed in the vicinity of each artificial gap and control site to quantify water flow intensity by their dissolution (Komatsu \& Kawai 1992). The cylinders measured $8 \mathrm{~cm}$ in height and $2.5 \mathrm{~cm}$ in diameter, and their ends were covered with a layer of epoxy glue to prevent dissolution, thus minimizing changes in exposed area due to erosion. Before placement out in the field, the cylinders were air dried for $30 \mathrm{~d}$, individually labelled and weighed. Two cylinders per site were set out on 21 October 2004. They were placed on rocks as near as possible to the control or gap location and fixed vertically $2 \mathrm{~cm}$ above the substratum by means of an anchored metal rod running through their centre. They remained exposed for $24 \mathrm{~h}$ (2 tidal cycles). After removal, the cylinders were again air dried for $30 \mathrm{~d}$ and reweighed. Weight loss was used as an index of water motion at each site (Guichard \& Bourget 1998). Although hydrodynamic conditions vary over much 
larger temporal scales than $24 \mathrm{~h}$, our flow measurements were used as an index of among-site spatial variability in the intensity of water motion.

Statistical analysis. In the colonization experiment, the null hypothesis tested was that transplant density and the presence of crevices would not affect the density and biomass of Mytilus spp. colonization. This hypothesis was tested on mussel density collected on each sieve or grouped as recruits versus larger juveniles and adults, using a mixed ANOVA model (Table 2) and analysed using the SAS statistical package. Fixed effects were transplant density (control, low and high) and quadrat position (1 to 9) relative to the crevice (4 to 6) and transplant (5). The interaction between density and quadrat treatments allowed separating the effects of crevices and transplants because crevices were present on the same quadrats across all density treatment levels. The ANOVA model included a random effect associated with among-site variability (site[density]). Residuals were visually inspected, and square-root transformations were applied to recruit and adult Mytilus spp. counts to meet assumptions of normality and homoscedasticity. Significant interactions or main effects were further analysed using leastsquares mean comparisons with significance level adjusted for the number of comparisons.

Because transplant mussels could move into neighbouring quadrats, we further explored causes of mussel colonization of cleared quadrats (1 to 4, 6 to 9), and partitioned the effects of within-quadrat transplant density and of local density dependence directly resulting from the transplant in the centre quadrat. We more precisely controlled for the presence of transplant mussels in non-transplant quadrats, by applying our ANOVA after removal of the centre quadrat from our data set and with transplant density in each quadrat as a co-variate in the resulting ANCOVA model. The lack of significant effect of our co-variate (within-quadrat transplant density) on colonization was interpreted as the direct effect of local density dependence (presence of a transplant in centre quadrat) on mussel colonization in cleared neighbouring quadrats.

For the gap experiment, we tested the null hypothesis of no effect of artificial gap size on increase in surrounding gap area between sampling dates. This was tested using a repeated-measure ANOVA model and implemented as a MANOVA in SAS. The main treatment was initial gap size (controls, $25 \mathrm{~cm}, 50 \mathrm{~cm}$ ), and gap size increments (controlling for initial size) at each date of observation were treated as response variables. The error term for our main treatment was site variability within gap size treatment (site[gap size]). The analysis was repeated with plaster cylinder dissolution as a co-variate to test the effect of flow intensity on gap propagation.
Table 2. Mytilus spp. ANOVA showing the effect of density, position (quadrat) and among-site variability on the colonization frequency of recruits and adults. The effect of transplant density (transplant mussels) is also shown

\begin{tabular}{|c|c|c|c|c|}
\hline Source of variation & df & MS & $F$ & $\mathrm{p}$ \\
\hline \multicolumn{5}{|l|}{ Recruits } \\
\hline Density & 2 & 84.0667 & 13.05 & 0.0001 \\
\hline Quadrat & 8 & 131.8389 & 20.47 & 0.0001 \\
\hline Site(Density) & 42 & 11.9196 & 1.85 & 0.0017 \\
\hline Density $\times$ Quadrat & 16 & 35.6583 & 5.54 & 0.0001 \\
\hline Error & 336 & 6.4414 & & \\
\hline Total & 404 & & & \\
\hline \multicolumn{5}{|c|}{ Recruits (excluding Quadrat 5) } \\
\hline Density & 2 & 10.6361 & 1.86 & 0.1688 \\
\hline Quadrat & 7 & 8.2917 & 3.03 & 0.0044 \\
\hline Site(Density) & 42 & 5.7286 & 2.09 & 0.0002 \\
\hline Density $\times$ Quadrat & 14 & 2.6298 & 0.96 & 0.4946 \\
\hline Error: MS(Site(Density) & y)) 42 & 5.7286 & & \\
\hline Error: MS(Error) & 294 & 2.7390 & & \\
\hline \multicolumn{5}{|c|}{ Recruits (excluding Quadrat 5) with transplant co-variate } \\
\hline Density & 2 & 9.2582 & 1.92 & 0.1568 \\
\hline Quadrat & 7 & 6.6813 & 2.43 & 0.0195 \\
\hline Site(Density) & 42 & 5.3120 & 1.93 & 0.0009 \\
\hline Density $\times$ Quadrat & 14 & 2.3469 & 0.85 & 0.6089 \\
\hline Transplant mussels & 1 & 0.7872 & 0.29 & 0.5927 \\
\hline Error & 52.71 & 4.8238 & & \\
\hline Error: MS(Error) & 293 & 2.7457 & & \\
\hline \multicolumn{5}{|l|}{ Adults } \\
\hline Density & 2 & 3939.7062 & 13.54 & 0.0001 \\
\hline Quadrat & 8 & 6959.1173 & 23.91 & 0.0001 \\
\hline Site(Density) & 42 & 608.4734 & 2.09 & 0.0002 \\
\hline Density $\times$ Quadrat & 16 & 1701.8145 & 5.85 & 0.0001 \\
\hline Error & 336 & 291.0543 & & \\
\hline Total & 404 & & & \\
\hline \multicolumn{5}{|c|}{ Adults (excluding Quadrat 5) } \\
\hline Density & 2 & 546.9361 & 2.14 & 0.1304 \\
\hline Quadrat & 7 & 676.1425 & 5.47 & 0.0001 \\
\hline Site(Density) & 42 & 255.6706 & 2.07 & 0.0003 \\
\hline Density $\times$ Quadrat & 14 & 285.9806 & 2.31 & 0.0050 \\
\hline Error: MS(Site(Density) & y)) 42 & 255.6706 & & \\
\hline Error: MS(Error) & 294 & 123.6969 & & \\
\hline \multicolumn{5}{|c|}{ Adults (excluding Quadrat 5) with transplant co-variate } \\
\hline Density & 2 & 143.5807 & 0.70 & 0.5016 \\
\hline Quadrat & 7 & 237.3499 & 2.01 & 0.0541 \\
\hline Site(Density) & 42 & 225.8434 & 1.91 & 0.0011 \\
\hline Density × Quadrat & 14 & 116.4204 & 0.98 & 0.4692 \\
\hline Transplant mussels & 1 & 1713.9830 & 14.49 & 0.0002 \\
\hline Error & 52.86 & 205.3788 & & \\
\hline Error: MS(Error) & 293 & 118.2693 & & \\
\hline
\end{tabular}

\section{RESULTS}

\section{Colonization}

Size structure of Mytilus spp. colonization

Mytilus spp. colonization at the experimental sites largely consisted of small to large adult mussels (Fig. 3). The mean density of recruits $(<4 \mathrm{~mm}$ shell length; Table 1) and larger juveniles and adults (4 to 


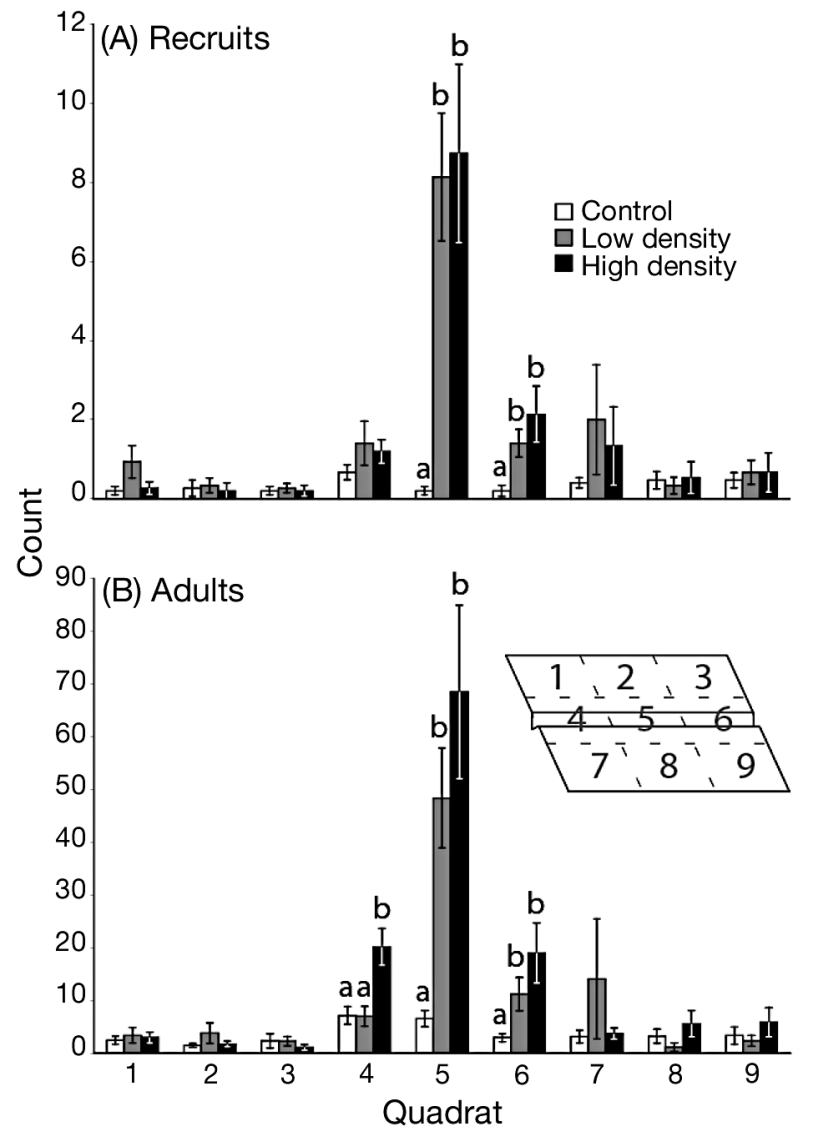

Fig. 3. Mytilus spp. Mean ( \pm SE) number of (A) recruits and (B) adults colonizing the quadrats for each density treatment. On both graphs, significant differences between quadrats at control, low-density and high-density transplant sites are indicated with different lower-case letters according to a least-squares mean comparison test $(\alpha=0.0250)$

$32 \mathrm{~mm}$ shell length; Table 1) collected were 33.8 and 254.7 individuals site ${ }^{-1}$, respectively. Of the adult mussels, $39 \%$ were collected in the $2 \mathrm{~mm}$; $53 \%$, in the $4 \mathrm{~mm}$; and $8 \%$, in the $9.5 \mathrm{~mm}$ sieve. Adults accounted for $91 \%$ of Mytilus spp. colonizers at the control, for $87 \%$ at the low-density treatment and $89 \%$ at the high-density treatment sites. Overall, nearly $89 \%$ of the colonizing mussel population was represented by adults $>4 \mathrm{~mm}$ shell length.

\section{Effect of mussel transplants and topography on colonization}

The interaction between transplant density and quadrat was significant for both recruit and adult colonizers ( $p<0.0001$; Table 2$)$. This result indicates that colonization by both recruits and adults increased with transplant density and topographic complexity (crevice vs. flat substratum; Fig. 2). Colonization on the transplant (Quadrat 5) was significantly higher than colonization on all other quadrats for both low- and high-density transplants (see multiple comparison results in Table 3). There was also a significant interaction between transplant density and quadrat position, with greater mussel colonizer density in crevices with neighbouring mussel transplants than at control sites (Fig. 3). Crevices received more colonizing mussels (recruits and adults) than smooth surfaces in highdensity transplant sites, whereas, at low-density transplant sites, this effect was significant only for adult mussels (Table 3). Although position also influenced colonization intensity at control sites, no effect of habitat types (crevice and smooth surfaces) could be detected (Table 3). Fucus spp. biomass, as a quantitative co-variate added to our main ANOVA model, had a significant, positive effect on recruit $(p<0.0001)$ and adult mussel $(p=0.0020)$ densities, but did not affect the significance of our main treatments. No significant effect of treatments was found when adult mussel densities were analysed separately for each sieve size (not shown).

In addition to increased Mytilus spp. colonization within experimental transplants, we observed increased numbers of colonizers in the vicinity of the mussel transplants (Fig. 3, Table 1). While control sites allowed testing for the effect of topography (crevice in centre of sites), this result could still be explained by 2 non-exclusive mechanisms: colonizers could aggregate in response to transplants, thus leading to a local (between-quadrat) density dependence, or they could aggregate in response to transplant mussel movement into neighbouring quadrats (Fig. 4), a response similar to the increased colonization within transplants. To control for these confounded effects, we partitioned the effect of transplant density within transplants, from

Table 3. Mytilus spp. Results from multiple comparison tests for the Density $\times$ Quadrat interaction effect on recruit and adult densities (see Fig. 2 for meaning of quadrat numbers). Least-squares mean comparisons were performed among quadrats for each mussel transplant density $(\alpha=0.0063)$. A continuous line joins quadrats that showed no significant differences

\begin{tabular}{|c|c|c|c|c|c|c|c|c|c|}
\hline Density & \multicolumn{9}{|c|}{ Quadrat } \\
\hline \multicolumn{10}{|l|}{ Recruits } \\
\hline Controls & 1 & 2 & 3 & 4 & 5 & 6 & 7 & 8 & 9 \\
\hline Low density & 5 & $\underline{1}$ & 2 & 3 & 4 & 6 & 7 & 8 & 9 \\
\hline High density & 5 & 6 & 4 & 7 & 1 & 8 & 9 & 2 & 3 \\
\hline \multicolumn{10}{|l|}{ Adults } \\
\hline Controls & 5 & 1 & 2 & 4 & 6 & 7 & 8 & 9 & 3 \\
\hline Low density & 5 & $\underline{6}$ & 4 & 7 & 1 & 2 & 3 & 9 & 8 \\
\hline High density & 5 & $\underline{4}$ & 6 & $\overline{\overline{1}}$ & 2 & 3 & 7 & $\overline{8}$ & 9 \\
\hline
\end{tabular}




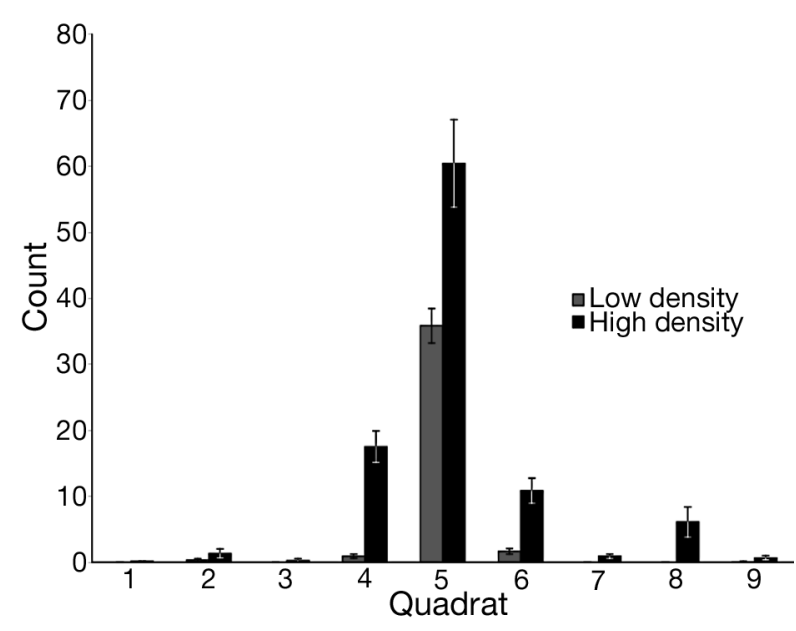

Fig. 4. Mytilus spp. Mean $( \pm \mathrm{SE})$ number of transplant marked mussels per quadrat found at the end of the experiment in transplant treatment sites

their effect caused by the movement of transplant mussels into neighbouring quadrats. More precisely, we performed an ANCOVA excluding the centre quadrat (5) and using as a co-variate the density of transplant mussels observed in each neighbouring quadrat as a result of their movement from the transplant (see also 'Materials and methods, Statistical analysis'; Fig. 4). The effect of the co-variate (transplant mussel density in neighbouring quadrats) was significant for adults $(p=0.0002)$, but not for recruits $(p=0.5927$; Table 2$)$. When the effect of transplant mussels in neighbouring quadrats was taken into account, no interaction between transplant density and quadrat position treatments was found for adult colonizers, suggesting a within-quadrat aggregation with transplant mussels. For recruit mussels, there was no significant effect of the co-variate, which suggests that the increased recruit density in quadrats outside of the transplant treatment was caused by a direct local density dependence associated with transplants.

\section{Adult displacement}

Marked mussels originating from the transplant sites moved throughout the intertidal zone of the study area from 1 June to 1 August (Fig. 5). We quantified this movement to examine the displacement distribution of adult mussels over an intertidal landscape. All transplant mussels found outside their initial site were alive and attached to the substratum. At lowdensity transplant sites, $71.7 \%$ of the transplant mussels still remained in their centre quadrat at the end of the summer, while $6 \%$ had moved to the other 8

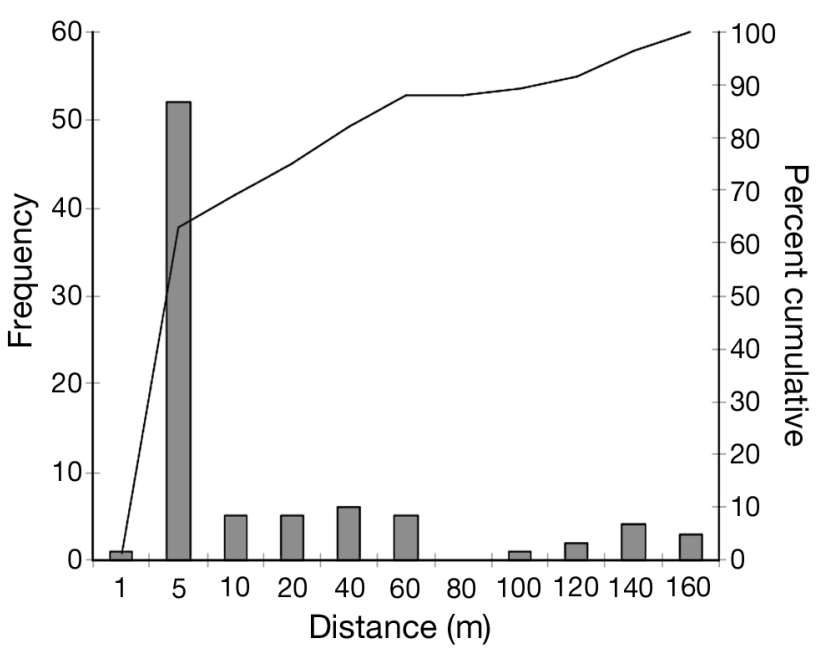

Fig. 5. Mytilus spp. Cumulative (line) and non-cumulative (bars) frequency distribution of displacement distance of marked mussels from initial position in experimental transplants

quadrats (Fig. 4). Only 4 (0.5\%) transplant mussels from low-density transplant sites were detected beyond the boundaries of their initial $50 \times 50 \mathrm{~cm}$ sites. At high-density transplant sites, 34.6 and $21.6 \%$ of transplant mussels were collected from the centre and other quadrats, respectively. A total of $80(3 \%)$ highdensity transplant mussels were discovered outside their $50 \times 50 \mathrm{~cm}$ experimental site. Furthermore, $21.7 \%$ of transplant mussels from low-density sites and $40.8 \%$ from high-density sites were never found in the study area, which characterizes the maximum potential mortality rate sustained by transplant mussels during our study. The modal and mean displacements of the 84 transplant mussels located outside their sites were 4.72 and $23.70 \mathrm{~m}$, respectively; the minimum distance travelled was $0.79 \mathrm{~m}$, and the maximum, $150.14 \mathrm{~m}$ (Fig. 5).

\section{Spread of artificial gaps}

For each treatment type (control, small gap, large gap), there was a significant difference in gap size between sampling times (Fig. 6). Eleven days after the creation of the artificial gaps, there was a small but significantly different $(\mathrm{p}<0.0001, \mathrm{df}=2, F=16.16)$ difference in gap expansion (increase from initial gap size) between control, small and large gaps, with gap-area increase significantly higher at large than at small gaps, both of which were also greater than at control sites. Two months later, in October, the percent gap cover at control sites was $42.7 \%$, while it was 70.7 and $73.9 \%$ at small and large gap sites, respectively; however, differences among gap size treatments were not 




Fig. 6. Total gap area connected to control, small $(25 \times 25 \mathrm{~cm})$ and large $(50 \times 50 \mathrm{~cm})$ gap sites as a function of time after creation of experimental gaps. Gap size has a significant effect on total (continuous) gap area on 27 August $(p<0.0001)$

significant ( $\mathrm{p}=0.058, \mathrm{df}=2, F=3.17$ ). A follow-up in late spring revealed the total absence of the mussel bed used for the experiment. These results imply that the early spread of disturbance depended on initial gap size, but, following 2 mo of wave-induced disturbance events, sites displayed similar gap sizes irrespective of starting conditions because of connectivity developing among gap and control sites. There was no relation between flow conditions as measured by plaster cylinders and gap expansion.

\section{DISCUSSION}

Our results suggest that in subarctic intertidal habitats, up to $90 \%$ of local Mytilus spp. colonization during the peak recruitment period (July to August) can be controlled by displacement of larger juveniles and adults (4 to $32 \mathrm{~mm}$ shell length) at scales $>10 \mathrm{~m}$ and by aggregation within and next to resident mussel aggregates. Disturbance of individual adults can be propagated by a similar spatially correlated process within existing mussel beds. We were further able to partition the effect of habitat type (topography) and transplant mussel density both within and among neighbouring quadrats, on colonization by recruits and adult mussels. What is important in these results is the reported small spatial scale $(\sim 100 \mathrm{~m})$ at which mussel population dynamics can operate through the positive feedback (aggregation) involved in colonization and distur- bance processes. Given the importance of recruitment over larger temporal and spatial scales, our results reveal multiple scales of connectivity and demographic coupling in age-structured benthic communities and provide the first quantification (frequency distribution) of distance of adult mussel movement in intertidal landscapes.

\section{Demographic and spatial structure of Mytilus colonization}

Regardless of transplant density, about $90 \%$ of colonizing mussels were of (reproductive and nonreproductive) adult size (4 to $32 \mathrm{~mm}$ ). Hunt \& Scheibling (1996) documented the settlement of post-larval mussels on natural substrata in a temperate system in which only 20 to $31 \%$ of colonizers measured 5 to $12 \mathrm{~mm}$. In another study, most colonizers were either recruits ( 0.5 to $1.9 \mathrm{~mm}$ ) or small juveniles (2 to $4.9 \mathrm{~mm}$; Hunt \& Scheibling 1998). An experiment using mussel transplants revealed that most colonizers were recruits $<2 \mathrm{~mm}$ shell length, while individuals measuring 2 to $10 \mathrm{~mm}$ only contributed to $<15-20 \%$ of colonization (Hunt \& Scheibling 2001). In our study, mussels of 1.9 to $4 \mathrm{~mm}$ shell length were referred to as recruits and only accounted for approximately $11 \%$ of colonization. This is potentially an overestimation of recruitment (individuals that recruited in the year of study), given slow shell growth rates in this subarctic intertidal environment (Guichard et al. 2001). It is also possible that our study missed small recruits $<1 \mathrm{~mm}$ (minimum expected shell length collected on the $0.5 \mathrm{~mm}$ sieve) at the end of our experiment. However, the overall large shell sizes of colonizing mussels suggest that, on this shore of the St. Lawrence Estuary, and over the temporal and spatial scales of our experiment, recruitment and growth (Petraitis 1995) are not the dominant processes upholding the observed patterns of Mytilus spp. colonization. The direct effects of pre- and post-settlement processes explaining our results are still unresolved, and mussel recruitment is highly variable between years in our study area (Smith 2007). Future studies should therefore test how our conclusions hold against spatial and temporal variability in the intensity of pre- and post-settlement processes.

Direct causes of adult mussel aggregation can be diverse, and could be associated with active or with passive mechanisms linked to hydrodynamic forces. Here, we report increased colonization with mussel transplant density. Other studies have used mussel transplants to assess mussel growth, vulnerability to predation and settlement of new individuals (Okamura 1986, Hunt \& Scheibling 2001). Our results further 
elucidate the process of local propagation in natural mussel aggregations as a result of positive density dependence during colonization and of small-scale movement of resident individuals. By incorporating the interaction between topographic heterogeneity and mussel density, our results also extend the positive effect of topographic heterogeneity (Archambault \& Bourget 1996) on mussel bed expansion. Our results confirm the critical importance of small-scale topographic heterogeneity for mussel colonization demonstrated in similar subarctic (Bergeron \& Bourget 1986), temperate (Erlandsson et al. 2005) and tropical (Menge et al. 1985) intertidal systems. They more specifically indicate that both colonization of bare substratum and colonization next to existing mussel beds are strongly dependent upon the presence of crevices. Such strong interaction between topographic heterogeneity and aggregation should be integrated within any predictive model of mussel bed dynamics. One important result, stemming from our ability to disentangle density-dependent colonization within quadrats from density-dependent effects observed between quadrats, exemplifies the idea of spatially explicit interactions in spatial ecology (Wootton 2001).

Local interactions such as competition, predation and facilitation between neighbouring Mytilus spp. individuals have been suggested in mussel population models (Wootton 2001, Guichard et al. 2003). Such local interactions involve a density-dependent effect over short distances. When measured in natural systems, it can be detected as within-quadrat density dependence, or, over larger scales, as betweenquadrat density dependence. Here, we show that both spatially correlated processes can operate during colonization by individual mussels, thus facilitating propagation of the mussel bed to neighbouring habitats. We showed how small individuals ( $<4 \mathrm{~mm}$ shell length) aggregate through between-quadrat density dependence, independently from within-quadrat mussel density. Our results provide empirical evidence and they quantify the scales ( 0.01 to $0.1 \mathrm{~m}$ ) of local processes, including the size-dependent aggregation of individual mussels in subarctic systems. They should therefore have strong implications for spatially explicit models that are currently used to predict landscape (Levin 1992, Wootton 2001, Guichard et al. 2003) and larger scale (Gouhier \& Guichard 2007) dynamics in temperate systems.

\section{Disturbance}

Following their creation in late summer, large gaps initially spread more rapidly than small gaps and controls. This spatial correlation in disturbance process can be explained by drag forces, acting horizontally to the bed, which apply pressure on the edges of a gap and potentially contribute to the propagation of disturbance (Denny 1987). It can also be understood as a spreading or 'infectious' disturbance similar to forest fire dynamics (Wootton 2001, Guichard et al. 2003). Although mussels on the edges of a bed usually display greater tenacity to wave disturbance, individuals on the edge of a newly created gap have not yet produced byssal threads normally elicited by increased flow exposure (Bell \& Gosline 1997). The spread of disturbance initially occurred at higher rates at gap sites than at controls, but the high level of connectivity between gap and control sites led to similar disturbed areas across treatment levels only 2 mo through the experiment when most of the mussel bed had been disturbed.

Such local density dependence in the acceleration of disturbance has been observed in the North East Pacific. Dayton (1971) witnessed exponential growth of natural gaps, whereas Paine \& Levin (1981) reported lognormal distribution of gap size and did not observe the expansion of gaps following their initial creation ( $\sim 3$ to $150 \mathrm{~cm}$ length). Guichard et al. (2003) reported power law (scale free) distribution of gaps and quantified how recently disturbed areas facilitated further disturbance in neighbouring mussel beds, suggesting that gap size is a dynamic variable, with gap size distribution at any given time not expected to reflect the size of newly created gaps. Our results demonstrate that such spatially correlated wave disturbance also applies to subarctic and estuarine systems where ice scouring was assumed to be the major cause of disturbance. In our results, small $(<0.5 \times 0.5 \mathrm{~m})$ artificial gaps are associated with the disturbance of an entire mussel bed ( 100 m length). Similar scale disturbances have been recently observed in natural mussel beds in the St. Lawrence Estuary, which stress the need to link mussel bed dynamics across spatial and temporal scales of disturbance and recovery. However, the generalization of these results to long-term mussel bed dynamics will require further studies considering seasonal variability in wave force and in the attachment strength of mussels (Carrington 2002).

It is also important to note that the disappearance of mussel beds within our $3 \times 3 \mathrm{~m}$ areas surrounding gaps corresponded to the disappearance of the entire mussel bed over $\sim 100 \mathrm{~m}$. Interestingly, numerous individual adult mussels were found at the location of the original mussel bed in May 2006 (F. Petrović pers. obs.), further supporting the suggestion that disturbance and colonization processes described here are important in structuring and explaining strong fluctuations of abundance in Mytilus spp. populations. 


\section{Adult displacement and scales of connectivity}

While theories of benthic invertebrate populations have historically assumed no connectivity between populations resulting from the limited movement or dispersal of individuals (Levin \& Paine 1974), more recent studies have identified larval dispersal as an important mechanism of connectivity between intertidal populations (Levin 2006). Estimates of dispersal distance of mussel larvae range from 10 to $100 \mathrm{~km}$ (Becker et al. 2007, Smith 2007), suggesting that populations regulated by larval supply operate at those scales. Our results show that in intertidal populations where colonization is in part controlled by adult displacement, demographic connectivity also operates within landscapes (0.01 to $0.1 \mathrm{~km}$ ).

We quantified the importance and scale of passive movement by adult Mytilus spp. (25 to $40 \mathrm{~mm}$ shell length) caused by wave action in the intertidal zone. Among all marked individuals, many remained within the confines of the $50 \times 50 \mathrm{~cm}$ sites - at most, displaced 5 to $15 \mathrm{~cm}$ from the transplant. Active crawling behaviour (Schneider et al. 2005) generally takes place within a few centimetres and usually occurs on a time scale of months, and wave disturbance is also a source of passive movement on a scale of 10s of centimetres (Hunt \& Scheibling 1998). Similar displacement of tagged mussels (5 to $25 \mathrm{~mm}$ shell length) was also documented on a temperate shore, most of which moved $<5 \mathrm{~cm}$ and 6 individuals which moved 10 to $49 \mathrm{~cm}$ (Hunt \& Scheibling 2002). In our study, 84 marked mussels were found established outside their original sites, with modal and maximum distances travelled of 4.7 and $150.1 \mathrm{~m}$, respectively. The only likely cause of displacement of $10 \mathrm{~s}$ to $100 \mathrm{~s}$ of metres over a period of 2 to 3 mo is dislodgement and transport by waves (Denny 1987, Hunt \& Scheibling 2001, 2002). Our study reveals the potential for wave disturbance to influence displacement and aggregation, but it is unclear how stronger wave disturbance regimes found in other intertidal systems could affect survival, displacement distance and successful reattachment of individual mussels.

Our results provide the first study of adult displacement distribution at the landscape level, and challenge the view of physical disturbance only as a source of mortality in intertidal communities (Dayton 1971, Paine \& Levin 1981). Indisputably, physical disturbance can lead to mortality, and our results suggest that $<20$ to $40 \%$ of displaced mussels either died or moved beyond the limits of our study area. Adult displacement distributions within landscapes can be statistically fitted to movement functions and integrated into spatially explicit models of coastal systems that more commonly implement connectivity through larval dispersal functions between landscapes (see Guichard et al. 2004 for a recent review). How these 2 spatial scales interact to explain regional population stability and persistence remains an open question, but recent studies point toward an important contribution of within-landscape connectivity (Gouhier \& Guichard 2007).

\section{Conclusions}

We demonstrate that Mytilus spp. passive adult movement can control up to $90 \%$ of local colonization over the main recruitment period (July to August) in a subarctic intertidal population, and occurs over spatial scales ranging from 1 to $100 \mathrm{~m}$, as waves dislodge and transport adult mussels throughout the intertidal zone. Colonization by recruits and adults involved in aggregation both within and next to mussel transplants is shown to result in the propagation of mussel beds at the local $(0.01$ to $0.1 \mathrm{~m})$ scale. We also show similar local propagating effects controlling rates of disturbances across connected mussel beds. One important implication of our results is the coupling between the disturbance and the colonization of individuals at the landscape level. Far from constituting a source of mortality, positive feedbacks involved during disturbance can be directly coupled to similar positive feedbacks during colonization over 1 to $100 \mathrm{~m}$. These dynamic and coupled processes force us to revisit the current paradigm of open and disturbed systems in intertidal populations where our results can be applied. They appear to play an important role in the maintenance of strong fluctuations in mussel populations and future research will more generally quantify the importance of adult displacement, recruitment, growth and survival on other subarctic and temperate rocky shores.

Acknowledgements. We thank G. Smith, J. F. Rivest, L. Galon and L. Duquenne for assistance during fieldwork. We also thank M. Fréchette and B. Chenard (Institut MauriceLamontagne, Fisheries and Oceans Canada) for access to basin and freezer space while in the field. We acknowledge the financial support from Fond Québécois de Recherche sur la Nature et les Technologies (FQRNT) and from the Natural Science and Engineering Research Council (NSERC). This study is a contribution to the program of Québec-Océan.

\section{LITERATURE CITED}

Archambault P, Bourget E (1996) Scales of coastal heterogeneity and benthic intertidal species richness, diversity and abundance. Mar Ecol Prog Ser 136:111-121

Bayne BL (1964) Primary and secondary settlement in Mytilus edulis L. (Mollusca). J Anim Ecol 33:513-523

Bayne BL (1965) Growth and delay of metamorphosis of the larvae of Mytilus edulis (L). Ophelia 2:1-47 
Becker BJ, Levin LA, Fodrie FJ, McMillan PA (2007) Complex larval connectivity patterns among marine invertebrate populations. Proc Natl Acad Sci USA 104:3267-3272

Bell EC, Gosline JM (1997) Strategies for life in flow: tenacity, morphometry, and probability of dislodgment of two Mytilus species. Mar Ecol Prog Ser 159:197-208

Bergeron P, Bourget E (1986) Shore topography and spatial partitioning of crevice refuges by sessile epibenthos in an ice disturbed environment. Mar Ecol Prog Ser 28:129-145

Caley MJ, Carr MH, Hixon MA, Hughes TP, Jones GP, Menge BA (1996) Recruitment and the local dynamics of open marine populations. Annu Rev Ecol Syst 27:477-500

Carrington E (2002) Seasonal variation in the attachment strength of blue mussels: causes and consequences. Limnol Oceanogr 47:1723-1733

Connell JH (1985) The consequences of variation in initial settlement vs. post-settlement mortality in rocky intertidal communities. J Exp Mar Biol Ecol 93:11-45

Connell JH, Hughes TP, Wallace CC (1997) A 30-year study of coral abundance, recruitment, and disturbance at several scales in space and time. Ecol Monogr 67:461-488

Dayton PK (1971) Competition, disturbance, and community organization: the provision and subsequent utilization of space in a rocky intertidal community. Ecol Monogr 41: 351-389

Denny MW (1987) Lift as a mechanism of patch initiation in mussel beds. J Exp Mar Biol Ecol 113:231-245

Erlandsson J, McQuaid CD, Kostylev VE (2005) Contrasting spatial heterogeneity of sessile organisms within mussel (Perna perna L.) beds in relation to topographic variability. J Exp Mar Biol Ecol 314:79-97

Fradette P, Bourget E (1980) Ecology of benthic epifauna of the Estuary and Gulf of St. Lawrence: factors influencing their distribution and abundance on buoys. Can J Fish Aquat Sci 37:979-999

Gaines SD, Roughgarden J (1985) Larval settlement rate: a leading determinant of structure in an ecological community of the marine intertidal zone. Proc Natl Acad Sci USA 82:3707-3711

Gouhier TC, Guichard F (2007) Local disturbance cycles and the maintenance of heterogeneity across scales in marine metapopulations. Ecology 88:647-657

Guichard F, Bourget E (1998) Topographic heterogeneity, hydrodynamics, and benthic community structure: a scale-dependent cascade. Mar Ecol Prog Ser 171:59-70

Guichard F, Bourget E, Robert JL (2001) Scaling the influence of topographic heterogeneity on intertidal benthic communities: alternate trajectories mediated by hydrodynamics and shading. Mar Ecol Prog Ser 217:27-41

Guichard F, Halpin PM, Allison GW, Lubchenco J, Menge BA (2003) Mussel disturbance dynamics: signatures of oceanographic forcing from local interactions. Am Nat 161:889-904

Guichard F, Levin SA, Hastings A, Siegel D (2004) Toward a dynamic metacommunity approach to marine reserve theory. BioScience 54:1003-1011

Hunt HL, Scheibling RE (1996) Physical and biological factors influencing mussel (Mytilus trossulus, M. edulis) settlement on a wave-exposed rocky shore. Mar Ecol Prog Ser 142:135-145

Hunt HL, Scheibling RE (1998) Spatial and temporal variability of patterns of colonization by mussels (Mytilus trossulus, M. edulis) on a wave-exposed rocky shore. Mar Ecol Prog Ser 167:155-169

Hunt HL, Scheibling RE (2001) Patch dynamics of mussels on rocky shores: integrating process to understand pattern. Ecology 82:3213-3231
Hunt HL, Scheibling RE (2002) Movement and wave dislodgment of mussels on a wave-exposed rocky shore. Veliger 45:273-277

Kautsky N (1982) Growth and size structure in a Baltic Mytilus edulis population. Mar Biol 68:117-133

Komatsu T, Kawai H (1992) Measurements of time-averaged intensity of water motion with plaster balls. J Oceanogr 48:353-365

Levin LA (2006) Recent progress in understanding larval dispersal: new directions and digressions. Integr Comp Biol 46:282-297

Levin SA (1992) The problem of pattern and scale in ecology. Ecology 73:1943-1967

Levin SA, Paine RT (1974) Disturbance, patch formation, and community structure. Proc Natl Acad Sci USA 71: $2744-2747$

Littorin B, Gilek M (1999) A photographic study of the recolonization of cleared patches in a dense population of Mytilus edulis in the northern Baltic proper. Hydrobiologia 393:211-219

McCook LJ, Chapman ARO (1997) Patterns and variations in natural succession following massive ice-scour of a rocky intertidal seashore. J Exp Mar Biol Ecol 214:121-147

McDonald JH, Seed R, Koehn RK (1991) Allozymes and morphometric characters of three species of Mytilus in the Northern and Southern Hemispheres. Mar Biol 111: 323-333

Menge BA, Lubchenco J, Ashkenas LR (1985) Diversity, heterogeneity and consumer pressure in a tropical rocky intertidal community. Oecologia 65:394-405

Menge BA, Daley BA, Wheeler PA, Dahlhoff E, Sanford E, Strub PT (1997) Benthic-pelagic links and rocky intertidal communities: Bottom-up effects on top-down control? Proc Natl Acad Sci USA 94:14530-14535

Menge BA, Lubchenco J, Bracken MES, Chan F and others (2003) Coastal oceanography sets the pace of rocky intertidal community dynamics. Proc Natl Acad Sci USA 100: 12229-12234

Moreau V, Tremblay R, Bourget E (2005) Distribution of Mytilus edulis and $M$. trossulus on the Gaspe coast in relation to spatial scale. J Shellfish Res 24:545-551

Okamura B (1986) Group living and the effects of spatial position in aggregation of Mytilus edulis. Oecologia 69:341-347

Paine RT (1974) Intertidal community structure: experimental studies on the relationship between a dominant competitor and its principal predator. Oecologia 15: 93-120

Paine RT, Levin SA (1981) Intertidal landscapes: disturbance and the dynamics of pattern. Ecol Monogr 51:145-178

Petraitis PS (1995) The role of growth in maintaining spatial dominance by mussels (Mytilus edulis). Ecology 76: $1337-1346$

Qiu JW, Tremblay R, Bourget E (2002) Ontogenetic changes in hyposaline tolerance in the mussels Mytilus edulis and M. trossulus: implications for distribution. Mar Ecol Prog Ser 228:143-152

Rawson PD, Yund PO, Lindsay SM (2007) Comment on 'Divergent induced responses to an invasive predator in marine mussel populations'. Science 316:53

Roughgarden J, Iwasa Y, Baxter C (1985) Demographic theory for an open marine population with space-limited recruitment. Ecology 66:54-67

Schneider KR, Wethey DS, Helmuth BST (2005) Implications of movement behavior on mussel dislodgement: exogenous selection in a Mytilus spp. hybrid zone. Mar Biol 146: 333-343 
Sigurdsson JB, Titman CW, Davies PA (1976) The dispersal of young post-larval bivalve molluscs by byssus threads. Nature 262:386-387

Smith GK (2007) Scales of coupling between benthic adults and larval recruits in the St. Lawrence Estuary. MSc thesis, McGill University, Montreal

Sousa WP (1984) The role of disturbance in natural communities. Annu Rev Ecol Syst 15:353-391

Stirling HP, Okumus I (1994) Growth, mortality and shell morphology of cultivated mussel (Mytilus edulis) stocks cross

Editorial responsibility: Steven Morgan,

Bodega Bay, California, USA planted between 2 Scottish sea lochs. Mar Biol 119:115-123

Underwood AJ, Denley EJ (1984) Paradigms, explanations and generalizations in models for the structure of intertidal communities on rocky shores. In: Strong DR Jr, Simberloff D, Abele LG, Thistle AB (eds) Ecological communities: conceptual issues and the evidence. Princeton University Press, Princeton, NJ, p 151-180

Wootton JT (2001) Local interactions predict large-scale pattern in empirically derived cellular automata. Nature 413: $841-844$

Submitted: May 8, 2007; Accepted: September 14, 2007 Proofs received from author(s): February 19, 2008 